\title{
Correction to: Fractional strain energy and its application to the free vibration analysis of a plate
}

\author{
Zaher Rahimi $^{1}$ (D) Siros Shafiei ${ }^{2} \cdot$ Wojciech Sumelka ${ }^{3} \cdot$ Ghader Rezazadeh $^{1}$
}

Published online: 8 September 2018

(c) Springer-Verlag GmbH Germany, part of Springer Nature 2018

\section{Correction to: Microsystem Technologies}

https://doi.org/10.1007/s00542-018-4087-8

In the original article, one of the co-author's (Ghader Rezazadeh) surname has been published incorrectly. The correct surname should be Rezazadeh.

The original article has been corrected.

The original article can be found online at https:// doi.org/10.1007/s00542-018-4087-8.

Zaher Rahimi

st_z.rahimi@urmia.ac.ir

1 Mechanical Engineering Department, Urmia University,

Urmia, Iran

2 Faculty of Mechanical Engineering, Tabriz University, Tabriz, Iran

3 Poznan University of Technology, Institute of Structural Engineering, Piotrowo 5 Street, 60-965 Poznan, Poland 